\title{
Managers/Owners' Innovativeness and Electronic Commerce Acceptance in Chilean SMEs: A Multi-Group Analysis Based on a Structural Equation Model
}

\author{
Elizabeth E. Grandón ${ }^{1}$ and Patricio Ramírez-Correa ${ }^{2}$ \\ 1 Universidad de Bío-Bío, Information Systems Department, Concepción, Chile, egrandon@ubiobio.cl \\ 2 Universidad Católica del Norte, Engineering School, Coquimbo, Chile, patricio.ramirez@ucn.cl
}

Received 13 June 2017; received in revised form 22 January 2018; accepted 28 February 2018

\begin{abstract}
The aim of this paper is to study differences in the adoption of e-commerce associated with the level of managers/owners' innovativeness. The background utilized to estimate the respondents' favorable reception of e-commerce is a model based on the Theory of Planned Behavior, which has been extended to include perceived drivers and obstacles as antecedents of attitude toward e-commerce acceptance. Small and medium enterprises in Chile participated in the study. A Partial Least Squares multi-group test was employed to note differences between groups. The main conclusions of the study are: (1) the level of managers/owners' innovativeness differentiates between adopters and non-adopters of e-commerce of small and medium enterprises in Chile; (2) the Theory of Planned Behavior has been successfully used to explain the process of adoption of e-commerce among Chilean managers/owners; (3) there are significant relationships between both drivers and obstacles and attitude toward using e-commerce; (4) a strong and significant relationship exists between attitude and intention to use e-commerce. Results can be used by small and medium enterprises in developing countries to boost e-commerce adoption.
\end{abstract}

Keywords: Innovativeness, E-commerce, Adoption, Small and medium enterprises (SMEs), Structural equation modeling 


\section{Introduction}

E-commerce, defined as "the process of buying and selling products or services using electronic data transmission via the Internet and the www" [26] has been a topic widely studied among researchers in the MIS community. Ecommerce offers numerous opportunities for businesses to increase their performance and effective supplier/buyer partnerships through the creation of a web of business-to-business communication networks [24]. As a result, in 2015 over half of all Internet users worldwide shopped online - 24.3\% of the global population [17] - and these sales attained a total value of 994.5 million US dollars [5].

However, in spite of the many possible advantages of e-commerce and the great attention paid to it by governments, the adoption of e-commerce is not homogeneous. On the one hand, the United Nations Conference on Trade And Development (UNCTAD) B2C E-commerce Index indicates an average value of 52 for developing economies, well below that of developed economies, whose average value is 77 [89]. On the other hand, the adoption of ecommerce by small and medium-sized enterprises (SMEs) is much lower than that of large companies [25], [72]. This fact is of great importance considering that SMEs can significantly contribute to the economy and rapid growth of developing countries [60]. In Chile, for example, $98.5 \%$ of the firms are classified as SMEs, including employer and non-employer firms in all industries, but they only account for about $16 \%$ of total annual sales of the country [66]. According to a longitudinal survey [48], most of large companies in Chile utilizes e-commerce but only $37 \%$ of SMEs have embarked on this technology. Chile is a country with an approximate population of 18 million, with an annual economic growth of $1.6 \%$, where $66.5 \%$ households have access to the Internet [67]. It is considered the leading country in Latin America according to the e-commerce index, but far behind the e-commerce index of developed economies [84]. These figures make Chile a good case study for exploring the e-commerce adoption phenomenon within SMEs.

The literature points out drivers and obstacles of e-commerce in SMEs [13], [38], [49]. Regarding obstacles, previous studies indicate a range that includes the difficulty of implementation [13], [49], unsuitability for the company's way of doing business [38], [49], and market [13] and security concerns [38]. Furthermore, previous studies indicate a variety of drivers that include opportunities for company development and connection with customers [13].

The individual-level adoption of e-commerce has been a focus of research in the last decade. In this context the Theory of Planned Behavior (TPB: [3]) which hypothesizes that an individual's intention to perform the behavior in question is a determinant of that behavior - has been widely employed for predicting behavior in many settings [25], [36], [54], and particularly for e-commerce intentions in SMEs [25], [60], [78], [98]. Immersed in this theory, and according to Ajzen [3], personality traits play a significant role in explaining human behavior. Therefore, the adoption of e-commerce could be best explained by integrating some specific personality traits. In SMEs, the manager/owner has a high degree of influence on business decisions, due to both the small number of employees and the centralized decision-making process. In this sense, the perceptions of the manager/owner are closely aligned with the company's conduct [55]. In fact, manager'/owner's personality traits affect their business decisions. Given that personality traits are defined as "endogenous dispositions that follow intrinsic paths of development essentially independent of environmental influences" [53] (p. 173), different dispositions may expedite or obstruct business managements' actions and behavior [76]. Some examples are business creation [75], planning processes [52], strategic flexibility [59], interfirm networks [95] and the internationalization process [32]. Since innovativeness defined as the extent to which an individual adopts innovations earlier than other members of the same social context [82] - is conceptualized as a personality trait [20], it can influence a manager's business decisions. At the firm level, innovativeness affects marketing issues [34]. But is it possible that this trait affects the appraisal made by managers/owners of drivers and obstacles of e-commerce or that of e-commerce adoption? Overall, this study posits the following research questions: What are the factors that influence intention to adopt e-commerce by Chilean managers/owners of SMEs? Do personality traits affect the appraisal made by managers/owners of drivers and obstacles of e-commerce or that of e-commerce adoption?

In this context, this paper's objective is to study differences in the adoption of e-commerce in SMEs associated with the level of managers/owners' innovativeness, which has not yet been studied. Specifically, this study's main aim is to discover variances in the adoption of e-commerce for a sample of Chilean SMEs. In addition, a TPB- based model is tested extending previous knowledge by incorporating drivers and obstacles as antecedents of the attitude toward the adoption of e-commerce.

The rest of the paper is organized as follows: Section 2 carries out a review of the literature on e-commerce and proposes a model grounded on TPB to measure the acceptance of e-commerce by SMEs. Next, the results of applying the Partial Least Squares analysis to the research model for the entire sample, and the sub-samples of higher and lower levels of managers/owners' innovativeness are presented. Non-parametric tests were used to compare the measurement of the constructs, and a PLS multi-group test was employed to examine the differences between the groups. Finally, the conclusions, limitations, and suggestions for future work are set out. 


\section{Related Works, Hypotheses and Contributions}

This section establishes the theoretical basis of the study to develop the research hypotheses. It also highlights the contributions of the study.

\subsection{The Theory of Planned Behavior (TPB) and E-Commerce}

The Theory of Planned Behavior (TPB: [3]) has been widely used to successfully predict behavioral intentions of different kinds [9], [34] [45], [62], [85], [88]. It posits that behavior is influenced by an individual's intention to perform the behavior in question. In turn, the intention is determined by one's attitude, subjective norm (SNORM), and perceived behavioral control. Attitude toward the behavior refers to the degree to which a person has a favorable or unfavorable evaluation of the behavior in question. SNORM denotes the perceived social pressure to perform or not to perform the conduct. Finally, perceived behavioral control (PBC) reflects an individual's perceptions that personal and situational impediments to performing the behavior exist. The more favorable the attitude and SNORM with respect to a behavior and the greater the PBC, the stronger an individual's intention to execute the behavior under consideration should be [3]. PBC influences behavior indirectly through intentions, as well as directly when the person does not have complete control over that behavior and when the individual's perceptions of control are accurate [50]

Hassan, Shiu and Parry [28] systematically reviewed studies that utilized the TPB model across more than one country. They performed a systematic literature review for papers published since 2000 that applied the TPB in consumption-related topics. The authors found more than 350 articles with a cross-country application of the theory. In total, 28 different countries spanning all the continents were included in the study. They found some variations in the influence of attitude, SNORMs and PBC on intention across nations and contexts. Few of these studies included countries in Africa or South America and an even smaller number focused on the adoption of e-commerce. In an attempt to understand this phenomenon in SMEs in Chile, Nasco et al. [60] applied the TPB to model intentions. By using hierarchical regression analysis, they found that the attitude and SNORM constructs positively and significantly predict intention, while the PBC construct does not. These results were similar to those found by Grandón et al. [25], who compared alternative models (Theory of Reasoned Action - TRA - and the TPB) to explain e-commerce adoption among managers/owners of SMEs in Chile. Attitude and SNORM significantly predict e-commerce but PBC does not. Previous studies [11], [77], [80], [83], [91] do not show a consistent relationship between PBC and intention. Consequently, in order to validate the previous findings in the Chilean context using a new sample of managers/owners, the following hypotheses are suggested:

H1: There is a positive relationship between attitude toward e-commerce and the intention to adopt e-commerce by Chilean mangers/owners of SMEs.

H2: There is a positive relationship between behavioral subjective norm toward e-commerce and the intention to adopt e-commerce by Chilean managers/owners of SMEs.

H3: There is a positive relationship between perceived control of e-commerce and the intention to adopt e-commerce by Chilean managers/owners of SMEs.

\subsection{Drivers and Obstacles of E-Commerce}

MacGregor and Vrazalic [49] investigated e-commerce adoption barriers in 477 SMEs in Sweden and Australia. They found two distinct factors associated with the difficulty and unsuitability of deploying e-commerce. The difficulty factor included impediments such as the complexity of e-commerce implementation techniques, deciding which standard to use, obtaining funds to implement e-commerce, the lack of technical knowledge and the difficulty of finding time to devote to the implementation process. On the other hand, the unsuitability factor involved obstacles such as the inappropriateness of e-commerce to the organisation's products/services, the way the company does business, how the client does business, and the lack of perceived advantages of e-commerce implementation. In a similar line of inquiry, Kartiwi and MacGregor [38] examined barriers to e-commerce in a developing country (Indonesia) and compared them with those in a developed economy (Sweden). In both cases, they surveyed managers/owners of SMEs. The authors found that while Swedish respondents were more concerned with technical issues, the Indonesian respondents were more preoccupied by organizational obstacles. The perception that ecommerce is not suited to the way they do business emerged as the top impediment for both developing and developed countries. Security concerns appeared as an important barrier in the developing country. These results are similar to the ones found by Grandón and Duran's [23] exploratory study in Chile. They surveyed 42 managers/owners of SMEs and explored some obstacles and drivers of e-commerce adoption. Three salient dimensions - resources, the business model and trust - emerged as obstacles while improvement processes and relationships with clients arose as drivers. 
In a recent study, Daviy and Rebiazina [13] analyzed the barriers and drivers for e-commerce market development in Russia. They conducted 25 in-depth interviews with representatives of Russian Internet businesses and identified that the most significant obstacles had to do with market, infrastructure, and institutional issues. On the other hand, the most noticeable drivers were opportunities for company development and the connection with customers.

All the above studies have determined drivers and obstacles of e-commerce adoption. They have contributed to our understanding of the underlying factor structure of these constructs. However, it is still necessary to know whether these perceived drivers and impediments affect the attitudes of a person toward the adoption of e-commerce. Ajzen [3] pointed out the importance of incorporating some indirect measures or antecedents of the direct measures of attitude, SNORMs and PBC into behavior. In this current research, we have focused our attention on the antecedents of attitude which represents the favorable or unfavorable evaluation of the adoption of e-commerce. We posit that favorable evaluations denote drivers while unfavorable evaluations represent obstacles toward ecommerce adoption. Thus, we state the following hypotheses:

H4: There is a positive relationship between drivers and attitude toward the adoption of e-commerce by Chilean managers/owners of SMEs.

H5: There is a negative relationship between obstacles and attitude toward the adoption of e-commerce by Chilean managers/owners of SMEs.

The proposed TPB model including 5 hypotheses is shown in Figure 1.

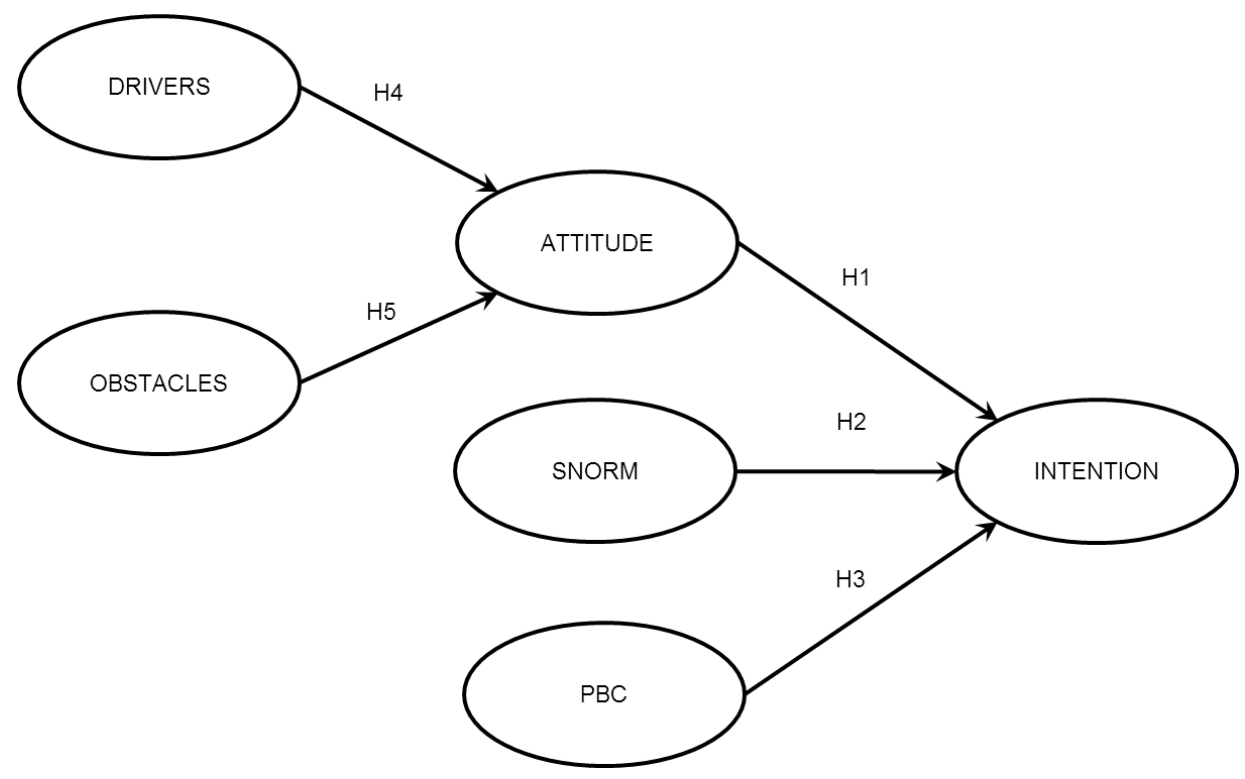

Figure 1: Proposed model

\subsection{Innovativeness}

Although there are many potential advantages of e-commerce (see e.g. [1], [4], [42], [58], the incorporation of ecommerce by SMEs remains limited. In Chile, for example, there is a big gap between the adoption rate of large companies and their small counterparts. Most large companies use e-commerce while only 37\% of SMEs do so [56] In order to promote the adoption of e-commerce among SMEs, especially in developing countries, researchers should incorporate other variants into the models that may account for a greater explanation of the phenomenon. As Ajzen [3] pointed out concepts referring to behavioural dispositions, such as social attitude and personality trait, have played an important role in these attempts to predict and explain human behavior (p.179). Walczak and Borkan [94] studied the effects of personality types on perceptions of online transactions. Ghobakhloo, Sabouri, Hong and Zulkifli [19] stated that innovativeness attributable to top management characteristics is another determinant of ecommerce applications adoption. Inspired by Ajzen's and Ghobakhloo et al.'s statements, we have included innovativeness as the personality trait that may contribute to differentiate between adopters and non-adopters of ecommerce in Chile.

There have been two streams of research that have focused on innovativeness as a personality trait. Agarwal and Prasad [2] developed the Personal Innovativeness Information Technology (PIIT) construct in the domain of information technology. They stated that PIIT has a moderating effect on the antecedents as well as the consequences of individual perceptions about a new information technology. They defined PIIT as the willingness of an individual to try out any new information technology (p. 206). The construct was operationalized and validated in 
a sample of 175 graduate students in the context of the World Wide Web. Many studies have used PIIT to learn its impact on the adoption of diverse types of technology [16], [87], [90].

Another research line focuses on the work of Parasuraman [68]. Based on extensive qualitative research on customer reactions to technology, the author developed the Technology Readiness Index (TRI) and conceptualized it through four dimensions: optimism, innovativeness, discomfort and insecurity. He defines innovativeness as a tendency to be a technology pioneer and thought leader (p. 311). The development of the TRI took place in conjunction with a company specialized in service and technology research. The first phases of the study ended up with the National Technology Readiness Survey (NTRS) that was refined in successive works. Parasuraman [56] operationalized the construct and worked out a multiple-item scale to measure TRI. He also assessed the scale's psychometric properties through telephone interviews with a random sample of 1000 individuals. This seminal work has been used to measure the innovativeness personality trait in various domains [14], [18], [41], [46], [93] and it has been applied in more than 30 countries.

Lin and Hsieh [47] refined Parasuraman's 36-item TRI across context and cultures to enhance the index's applicability and generalizability. Thus, a refined 16-item TRI scale was proposed and validated throughout different samples and methods. The four dimensions of the original scales remained stable, while the ease of application of the instrument increased due to the reduction in the number of questions.

More than a decade after its conception, Parasuraman and Colby [69] updated the TRI scale by reconsidering TRI statements based on new contexts, incorporating relevant implications of new technology environment, and making the instrument more parsimonious. Unlike Lin and Hsieh's work [47] cited above, Parasuraman and Colby [69] added different items and modified current scale items to address the new technological environment. They developed TRI 2.0 following a rigorous research method and validated it in two samples for a total of 878 individuals. As a result, they came up with a 16-item scale comprised of the same four dimensions (optimism, innovativeness, discomfort and insecurity) that explain $61 \%$ of the variance across the items. It is interesting to note the robustness of the innovativeness dimension, which remained unaltered in the second version of TRI.

The innovativeness construct has been included in different research models as a direct antecedent of the intention to use or to continue using Internet related technologies [35], [43], [73]. It has also been used as an antecedent of perceived ease of use and perceived usefulness of the Technology Acceptance Model [9]. For example, Lin, Shin and Sher [46] tested innovativeness construct as part of TRI and found that the relationship between perceived ease of use (PEOU) and perceived usefulness (PU) is stronger for PEOU than for PU, while Walczuch, Lemmink and Streukens [93] noticed that there is a significant negative relationship between innovativeness and PU. In a more recent study, Shin and Lee [86] detected that innovativeness has a positive effect on consumers' PEOU of $m$ payment whereas Erdoğmuş and Esen [18] noted that innovativeness has no impact on either PEOU or usefulness. These mixed results suggest there may be other ways in which innovativeness influences the intention to adopt technology. Yousafzai and Yani-de-Soriano [97] followed this line of thought and considered innovativeness as a moderator of the relationship between PU and PEOU in the intention to adopt Internet banking among 435 UK users. Specifically, they stated that the relationship is stronger for respondents with a high level of innovativeness. Similarly, in a more current study, Borrero, Yousafzai, Javed and Page [8] used the Unified Theory of Acceptance and Use of Technology (UTAUT) [78] and found that innovativeness moderates the relationships between the constructs of UTAUT and the intention to use social network sites (SNS) for students in Spain. Following this line of analysis, we believe that the level of managers/owners' innovativeness influences the relationships of the constructs in the current research model differently. Therefore, we proposed the following hypotheses:

H6. There are statistically significant differences between higher and lower levels of managers/owners' innovativeness in the mean scores of each construct of the proposed research model.

H7. There are statistically significant differences between higher and lower levels of managers/owners' innovativeness in the relationships between the constructs of the proposed research model.

\subsection{Contribution of the Study}

The contributions of this study are three-fold. First, considering that there is a low development of B2C e-commerce in Chile and high rates of technological access [22], there are a limited number of studies that have attempted to explain this phenomenon. Some exceptions are Godoy and Helsper [21] and Godoy et al. [30] who have indicated that consumers might have low rates of banking and digital literacy and companies might have poor logistics for the delivery of goods purchased online. This current study aims to contribute to the explanation of this situation through a different behavioral perspective.

Second, we expect to shed some light on SMEs in order for them to consider personality traits as a factor that might promote or discourage e-commerce adoption. The incorporation of e-commerce in SMEs encloses new technology and the way business is done. This is important since it is known that the growth of countries is partially explained by the digital economy [65] where e-commerce plays a fundamental role. 
Third, this study intends to contribute with both practical and theoretical implications. It proposes some strategies that government could implement in order to promote e-commerce adoption among SMEs. It contributes to theory building by considering personality traits, particularly innovativeness, as an important factor in intention models. In addition, theory might be improved by incorporating drivers and obstacles as potential antecedents to attitude toward e-commerce adoption.

\section{Methodology}

This section explains the methodology developed to carry out the research. First, the procedure to collect data, the subjects who participated in the study, and the way subjects were contacted is described. Then, a description of the instrument utilized to collect data is given. Finally, the procedure used to perform statistical analysis is explained.

\subsection{Subjects}

Top managers/owners of SMEs in Santiago, the Biobío and Araucanía regions of Chile participated in this study. A random sample of 1000 SMEs was chosen from different business directories. The Chilean Ministry of Economics defines a small and medium size business as one that employs between 10 and 200 employees [57]. Telephone calls were made in order to verify the business addresses and the names of the managers/owners of the SMEs. Questionnaires were then sent via mail to the sample selected, along with a covering letter and a pre-paid return envelope. After three to four weeks, follow-up telephone calls were made to non-respondents. Two-hundred fifty six (256) surveys were returned over a 7 -week period (a $25.6 \%$ response rate).

We carefully screened respondents to ensure that each person was a primary decision-maker, a top manager/owner, that the firm met the definition of an SME and that it did not already have e-commerce in place. 210 questionnaires were left after excluding those which were invalid. Table 1 shows some demographics of the respondents grouped according to the level of managers/owners' innovativeness.

\subsection{Instrument Development}

The definition of e-commerce was given in the first paragraph of the questionnaire so that respondents understood the meaning of the term and answer the questions accordingly. The survey consists of two parts. The first included questions regarding perceptions of e-commerce, perceived obstacles and barriers to implementing the technology and the level of the managers/owners' innovativeness. The second was comprised of demographic data about the managers/owners.

We used Ajzen's [3] scale to measure the constructs associated with the TPB (ATTITUDE, SNORM, PBC and INTENTION). The drivers and obstacles were taken directly from an elicitation study conducted by Grandón and Mykytyn [24] based on a sample of 30 managers/owners of SMEs in Chile. These authors utilized the procedure suggested by Ajzen's Theory of Planned Behavior to elicit important beliefs associated with the intention to adopt ecommerce. Table 3 below shows all the final items used to measure these six constructs. Finally, questions regarding the managers/owners' innovativeness were taken from Parasuraman's TRI [68]: a) other people come to you for advice on new technologies, b) in general, you are among the first in your circle of friends to acquire new technology when it appears, c) you keep up with the latest technological developments in your areas of interest and d) you enjoy the challenge of figuring out high-tech gadgets.

\subsection{Procedure for Statistical Analysis}

Initially, the proposed model was validated for the whole sample. Then, the sample was separated into two groups: lower and higher levels of managers/owners' innovativeness. We divided the group between lower and higher levels of managers/owners' innovativeness based on mean scores. Innovativeness's factorial loadings were $>0.7$ for all items, and its Cronbach's Alpha was 0.773 . Due to data was not normally distributed, a nonparametric technique (Kruskal-Wallis) was applied to compare the two sets. Afterwards, SmartPLS software was used [79] and Multi-group PLS analysis was run to compare the differences between the groups.

\section{Results}

A preliminary analysis of the sectors indicated that there is not significant differences in means among the industries. The results of the descriptive statistics are shown in Table 2. The scale used is a 5-point Likert type. SPSS software was employed for this test. The Kruskal-Wallis test results indicated statistically significant differences between the scores of lower and higher level manager/owners' innovativeness in some variables: ATTITUDE, SNORM, DRIVERS, and OBSTACLES. Therefore, hypothesis $\mathrm{H} 6$ is partially accepted. 
Table 1: Descriptive statistics of the sample

\begin{tabular}{|c|c|c|c|c|}
\hline & \multicolumn{2}{|c|}{ Level of manager's innovativeness } & \multirow[b]{2}{*}{ Total } \\
\hline & & Lower & Higher & \\
\hline \multirow{2}{*}{ Gender } & Male (\%) & $127(79.9)$ & 45 (88.2) & $172(81.9)$ \\
\hline & Female (\%) & $32(20.1)$ & $6(11.8)$ & $38(18.1)$ \\
\hline \multirow{3}{*}{ Education } & Secondary (\%) & $19(12.0)$ & $2(3.9)$ & $21(10.0)$ \\
\hline & Tertiary $(\%)$ & $132(83.0)$ & $48(94.1)$ & $180(85.7)$ \\
\hline & Others (\%) & $8(5.0)$ & $1(2.0)$ & $9(4.3)$ \\
\hline \multirow{7}{*}{ Sector } & Commerce (\%) & $46(28.9)$ & $12(23.5)$ & $58(27.6)$ \\
\hline & Services (\%) & $41(25.8)$ & $16(31.4)$ & $57(27.1)$ \\
\hline & $\begin{array}{l}\text { Manufacture } \\
(\%)\end{array}$ & $24(15.1)$ & $8(15.7)$ & $32(15.2)$ \\
\hline & $\begin{array}{l}\text { Construction } \\
(\%)\end{array}$ & $11(6.9)$ & $4(7.8)$ & $15(7.2)$ \\
\hline & Forestry (\%) & $9(5.7)$ & $1(2.0)$ & $10(4.8)$ \\
\hline & Health (\%) & $9(5.7)$ & $0(0.0)$ & $9(4.3)$ \\
\hline & Others (\%) & $19(11.9)$ & $10(19.6)$ & $29(13.8)$ \\
\hline Total (\%) & & $159(7$ & $51(24.3)$ & $210(100.0$ \\
\hline
\end{tabular}

Table 2: Descriptive statistics and Kruskal-Wallis Test

\begin{tabular}{|l|l|l|l|}
\hline Latent variable & $\begin{array}{l}\text { Level of manager's } \\
\text { innovativeness }\end{array}$ & $\begin{array}{l}\text { Mean score } \\
\text { (SD) }\end{array}$ & $\begin{array}{l}\text { Chi-Square } \\
\text { (Sig.) }\end{array}$ \\
\hline INTENTION & Lower & $2.01(0.81)$ & 3.565 \\
\hline & Higher & $2.25(0.92)$ & $(.059)$ \\
\hline ATTITUDE & Lower & $2.68(0.69)$ & 6.024 \\
\hline & Higher & $2.95(0.66)$ & $(.014)$ \\
\hline SNORM & Lower & $2.23(0.67)$ & 6.701 \\
\hline & Higher & $2.51(0.75)$ & $(.010)$ \\
\hline PBC & Lower & $2.00(0.72)$ & 2.704 \\
\hline & Higher & $2.24(0.85)$ & $(.100)$ \\
\hline DRIVERS & Lower & $2.75(0.58)$ & 9.138 \\
\hline & Higher & $3.01(0.55)$ & $(.003)$ \\
\hline OBSTACLES & Lower & $2.00(0.83)$ & 4.583 \\
\hline & Higher & $1.72(0.85)$ & $(.032)$ \\
\hline
\end{tabular}

\subsection{Results from the Measurement Model}

A PLS approach is defined by two models: the measurement model and the structural model. As a previous step to the structural model analysis it is necessary to analyze the reliability and validity of the measurement model.

As shown in Table 3, and following Hair et al. [27] procedure to evaluate reflective measurement models, reliability was evaluated by examining individual loads or simple correlations of the measures with their respective latent variables ( $\geq .7$ were accepted). Cronbach's alpha coefficient was used as the reliability index of the latent variables. Furthermore, composite reliability was computed. The convergent validity of latent variables was evaluated by inspecting the average variance extracted (AVE) (> .5 were accepted). Discriminant validity of latent variables was verified utilizing the Fornell-Larcker criterion by examining whether the square root of the AVE of each one was over the correlations with the other latent variables [27]. As can be seen in Table 4, the square root of each construct's AVE is greater than its highest correlation with any other construct. 
Table 3: Cronbach's Alpha, AVE, Composite Reliability and Factor Loadings

\begin{tabular}{|c|c|c|c|c|}
\hline \multicolumn{2}{|l|}{ Items } & \multirow{2}{*}{\begin{tabular}{|l} 
All \\
.86
\end{tabular}} & \multirow{2}{*}{\begin{tabular}{|l|}
$\begin{array}{l}\text { Lower } \\
\text { innov. }\end{array}$ \\
.85 \\
\end{tabular}} & \multirow{2}{*}{\begin{tabular}{|l|}
$\begin{array}{l}\text { Highel } \\
\text { innov. }\end{array}$ \\
.88 \\
\end{tabular}} \\
\hline \multirow{3}{*}{$\begin{array}{l}\text { Behavioral intention } \\
\text { (INTENTION) }\end{array}$} & AVE & & & \\
\hline & Composite Reliability & .95 & .95 & .96 \\
\hline & Cronbach's Alpha & .92 & .91 & .93 \\
\hline INTENTION1 & $\begin{array}{l}\text { My firm strongly intends to incorporate e-commerce } \\
\text { within the next year }\end{array}$ & .93 & .92 & .95 \\
\hline INTENTION2 & $\begin{array}{l}\text { We have certain plans to incorporate e-commerce in } \\
\text { our organization within the next year }\end{array}$ & .94 & .95 & .93 \\
\hline INTENTION3 & $\begin{array}{l}\text { Our firm has a strong commitment to incorporating } \\
\text { e-commerce within the next year }\end{array}$ & .91 & .90 & .93 \\
\hline \multirow{3}{*}{$\begin{array}{l}\text { Attitude toward behavior } \\
\text { (ATTITUDE) }\end{array}$} & AVE & .78 & .79 & .72 \\
\hline & Composite Reliability & .91 & .92 & .89 \\
\hline & Cronbach's Alpha & .86 & .87 & .81 \\
\hline ATTITUDE1 & $\begin{array}{l}\text { Incorporating e-commerce in my firm within the next } \\
\text { year would be good }\end{array}$ & .87 & .89 & .82 \\
\hline ATTITUDE2 & $\begin{array}{l}\text { Incorporating e-commerce in my firm within the next } \\
\text { year would be positive }\end{array}$ & .91 & .92 & .87 \\
\hline ATTITUDE3 & $\begin{array}{l}\text { Incorporating e-commerce in my firm within the next } \\
\text { year would be effective }\end{array}$ & .86 & .86 & .86 \\
\hline \multirow{3}{*}{$\begin{array}{l}\text { Subjective norm } \\
\text { (SNORM) }\end{array}$} & AVE & .71 & .72 & 68 \\
\hline & Composite Reliability & .88 & .88 & .86 \\
\hline & Cronbach's Alpha & .79 & .80 & .77 \\
\hline SNORM1 & $\begin{array}{l}\text { Most people who are important to my firm think my } \\
\text { firm should incorporate e-commerce within the next } \\
\text { year }\end{array}$ & .78 & .78 & .79 \\
\hline SNORM2 & $\begin{array}{l}\text { Most people who influence the behavior of my firm } \\
\text { think my firm should incorporate e-commerce within } \\
\text { the next year }\end{array}$ & .86 & .87 & .84 \\
\hline SNORM3 & $\begin{array}{l}\text { People whose opinions our firm value would prefer } \\
\text { our firm to incorporate e-commerce within the next } \\
\text { year }\end{array}$ & .88 & .88 & .84 \\
\hline \multirow{3}{*}{$\begin{array}{l}\text { Perceived behavioral } \\
\text { control (PBC) }\end{array}$} & AVE & .75 & .71 & .86 \\
\hline & Composite Reliability & .90 & .88 & .95 \\
\hline & Cronbach's Alpha & .84 & .80 & .93 \\
\hline PBC1 & $\begin{array}{l}\text { Incorporating e-commerce in my firm within the next } \\
\text { year would be easy }\end{array}$ & .89 & .87 & .94 \\
\hline PBC2 & $\begin{array}{l}\text { Incorporating e-commerce in my firm within the next } \\
\text { year would be under my firm's control }\end{array}$ & .87 & .83 & .94 \\
\hline PBC3 & $\begin{array}{l}\text { Incorporating e-commerce within the next year } \\
\text { would be simple to arrange }\end{array}$ & .85 & .83 & .90 \\
\hline \multirow{3}{*}{$\begin{array}{l}\text { Perceived drivers } \\
\text { (DRIVERS) }\end{array}$} & AVE & .60 & .59 & .59 \\
\hline & Composite Reliability & .90 & .90 & .90 \\
\hline & Cronbach's Alpha & .87 & .86 & .86 \\
\hline DRIVERS1 & Enhancing your distribution process & .78 & .76 & .80 \\
\hline DRIVERS2 & To be seen as a more innovative company & .72 & .71 & .74 \\
\hline DRIVERS3 & Performing like a large company & .85 & .84 & .85 \\
\hline DRIVERS4 & Making better use of information & .77 & .76 & .76 \\
\hline DRIVERS5 & Cost reductions & .77 & .79 & .73 \\
\hline DRIVERS6 & Ease in reaching clients & .75 & .74 & .71 \\
\hline \multirow{3}{*}{$\begin{array}{l}\text { Perceived obstacles } \\
\text { (OBSTACLES) }\end{array}$} & AVE & .72 & .72 & .71 \\
\hline & Composite Reliability & .89 & .89 & .88 \\
\hline & Cronbach's Alpha & .81 & .81 & .81 \\
\hline OBSTACLES1 & E-.commerce is not secure & .85 & .86 & .89 \\
\hline OBSTACLES2 & $\begin{array}{l}\text { E-commerce is not suited to our way of doing } \\
\text { business }\end{array}$ & .85 & .84 & .88 \\
\hline OBSTACLES3 & E-commerce is too complicated to implement & .85 & .85 & .75 \\
\hline
\end{tabular}


Table 4: Discriminant validity for the whole sample

\begin{tabular}{|l|l|l|l|l|l|l|}
\hline & INTENTION & ATTITUDE & SNORM & PBC & DRIVERS & OBSTACLES \\
\hline INTENTION & .93 & & & & & \\
\hline ATTITUDE & .53 & .88 & & & & \\
\hline SNORM & .51 & .59 & .84 & & & \\
\hline PBC & .37 & .35 & .43 & .87 & & \\
\hline DRIVERS & .27 & .33 & .30 & .13 & .77 & \\
\hline OBSTACLES & -.38 & -.43 & -.46 & -.36 & -.23 & .85 \\
\hline
\end{tabular}

\subsection{Results from the Structural Models}

After examining the measurement model, the relations between the constructs were addressed. The hypotheses were verified by exploring path coefficients. A bootstrapping of 150 sub-samples was computed to check the statistical significance of each path. The variance explained (R-squared) of the endogenous latent variables and the $p$-values of the regression coefficients (F-test) work as indicators of the model's explanatory power.

The outcomes of multi-group analysis for the model with the groups of lower and higher level of managers/owners' innovativeness are shown in Table 5. Based on these results hypotheses $\mathrm{H} 1, \mathrm{H} 2, \mathrm{H} 3, \mathrm{H} 4$, and $\mathrm{H} 5$ are accepted because all the hypothesized relationships are statistically significant.

Table 5: Path coefficients

\begin{tabular}{|c|c|c|c|c|c|c|}
\hline Path & $\begin{array}{l}\text { Whole } \\
\text { sample } \\
\text { (Sig.) }\end{array}$ & $\begin{array}{l}\text { Lower } \\
\text { innov. } \\
\text { (Sig.) }\end{array}$ & $\begin{array}{l}\text { Higher } \\
\text { innov. } \\
\text { (Sig.) }\end{array}$ & $\begin{array}{l}\mid \text { Lower } \\
\text { innov.- } \\
\text { Higher } \\
\text { innov| }\end{array}$ & $\begin{array}{l}\text { Henseler's } \\
\text { p-value } \\
\text { (Sig.) }\end{array}$ & $\begin{array}{l}\text { Parametric } \\
\text { p value } \\
\text { (Sig.) }\end{array}$ \\
\hline ATTITUDE -> INTENTION & $.32\left({ }^{\star \star *}\right)$ & $.29\left(^{* * *}\right)$ & $.37\left(^{*}\right)$ & .09 & .33 (n.s.) & .59 (n.s.) \\
\hline SNORM -> INTENTION & $.26\left(^{* * *}\right)$ & $.26\left(^{* * *}\right)$ & $.25\left(^{*}\right)$ & .01 & .53 (n.s.) & .95 (n.s.) \\
\hline PBC -> INTENTION & $.15\left(^{*}\right)$ & $.21\left(^{\star *}\right)$ & .02 (n.s.) & .20 & .91 (n.s.) & .22 (n.s.) \\
\hline DRIVERS -> ATTITUDE & $.25\left(^{* \star *}\right)$ & .13 (n.s.) & $.58\left(^{\star \star \star}\right)$ & .45 & $.00\left({ }^{\star \star \star}\right)$ & $.00\left(^{\star \star}\right)$ \\
\hline OBSTACLES $->$ ATTITUDE & $-.38\left({ }^{* * *}\right)$ & $-.46\left(^{\star * \star}\right)$ & -.14 (n.s.) & .32 & $.01\left(^{* \star}\right)$ & $.02\left(^{*}\right)$ \\
\hline
\end{tabular}

Statistical significance: ${ }^{*} \mathrm{p}<0.05 ;{ }^{* *} \mathrm{p}<0.01 ;{ }^{* * *} \mathrm{p}<0.001 ;$ n.s: non-significant.

Finally, from Table 5 we can partially accept hypothesis $\mathrm{H} 7$, because statistically significant differences exist in some relationships between variables in our model. Figure 2 shows the result for the model considering the whole sample.

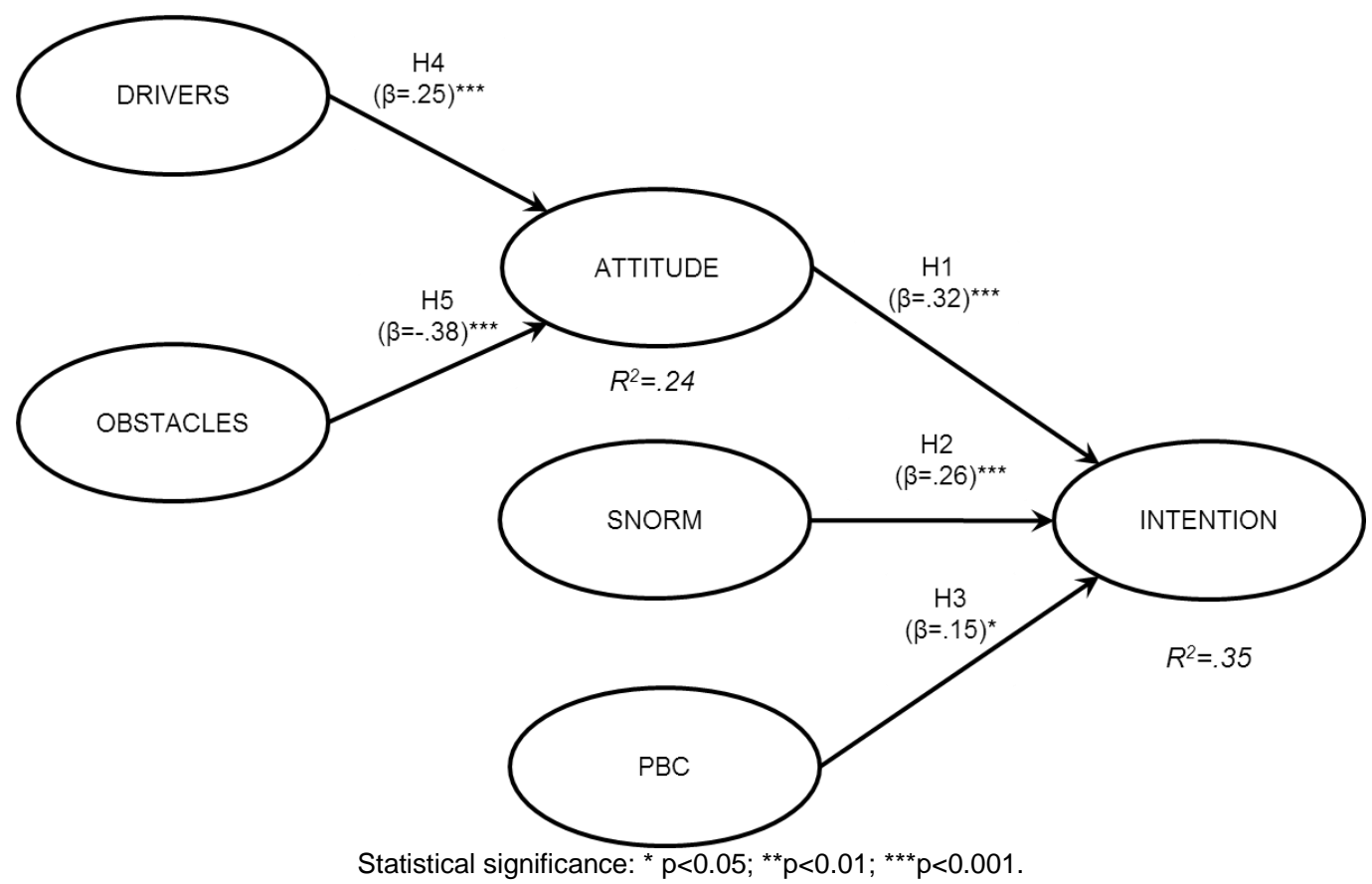

Figure 2: PLS results for the whole sample 


\subsection{Testing Model Fit}

First, the global fit of the model was evaluated through the Standardized Root Mean Square Residual (SRMR) indicator. Hu and Bentler [33] define SRMR as the root mean square discrepancy between the observed correlations and the model-implied correlations. SRMR can be used for evaluating the global fit of a research model in PLS and to avoid model misspecification [29] [64] . Henseler et al. [29] indicated that a cut-off value of 0.08 for SRMR appears to be more suitable in PLS. In this study, SRMR is equal to $0.064(<0.08)$ which means that the model fits the empirical data [27].

Moreover, the exact model fit was evaluated by a bootstrap routine for testing the statistical inference of the discrepancy between the empirical covariance matrix and the covariance matrix implied by the composite factor model. Henseler et al. [23] proposed the d_ULS (squared Euclidean distance) and d_G (geodesic distance) as the two different ways to compute this discrepancy. The bootstrap routine provides the confidence intervals of these discrepancy values. The fit criterion is that SRMR, d_UPS, and d_G associated to the saturated model from original sample should be less than the $95 \%$ bootstrapped quantile (HI95). In this study, SRMR (0.064) is less that HI95 of SRMR (0.071), d_ULS (0.949) is less that HI95 of d_ULS (1.111), and d_G (0.623) is less than HI95 of d_G (0.765), which means that the data fits the model well.

\section{Discussion}

This research sought to study differences in the adoption of e-commerce in SMEs associated with the level of managers/owners' innovativeness and to validate the applicability of the TPB by adding some antecedents (drivers and obstacles) that better explain the attitude toward e-commerce adoption. From the results based on the whole sample, we found that attitude emerged as the most significant predictor of adoption intention $(\beta=.32)$ compared to the SNORM $(\beta=.26)$ and PBC $(\beta=.15)$. If we analyze this situation in more detail, we find that for both more and less innovative managers/owners of Chilean SMEs, the attitude and SNORM constructs are significantly related to the intention to adopt e-commerce. Regardless of their level of innovativeness, managers/owners who have a positive attitude toward e-commerce and perceive social pressure from people and other firms to adopt it report higher intentions to adopt e-commerce in the future. These results are consistent with previous research based on managers/owners of SMEs [25], [60], [77]. However, if we look at the PBC construct in more depth, we see that the relationships between the construct and intention are significant only for managers/owners with a lower level of innovativeness. In other words, less innovative managers/owners perceive that there are personal and situational impediments to adopting e-commerce. In contrast, more innovative managers/owners do not perceive any impediments to adopting the technology. This may be an explanation for the inconclusive results found in previous studies regarding the applicability of the PBC construct as a predictor of e-commerce adoption. Personality traits, such as innovativeness, may play an important role in explaining when PBC performs as a significant antecedent of the intention to adopt e-commerce.

The results also indicate that favorable evaluations (drivers) positively impact the attitude towards the adoption of ecommerce while unfavorable evaluations (obstacles) negatively influence the attitude toward the adoption behavior. As we foresaw, both statements were found to be true and, more important, we detected interesting results. Drivers are significant predictors of attitude for more innovative managers/owners while obstacles are significant predictors of attitude for less innovative managers/owners. Particularly, managers/owners with a high level of innovativeness consider that e-commerce makes firms be seen as more innovative, enhances the distribution process, uses information better, and makes an SME perform like a large company. Conversely, managers/owners with a low level of innovativeness consider that e-commerce is not secure, is not suited to the way the company does business and is too complicated to implement. In other words, they only see unfavorable outcomes of the adoption of e-commerce which negatively influence their attitude toward it. Less innovative managers/owners do not take into account the drivers of e-commerce adoption and more innovative managers/owners do not take into account the obstacles of ecommerce adoption.

These novel findings have important practical implications. Chilean government has launched the 2020 Digital Agenda which incorporates important actions to enhance country's digital development and reduce the digital divide. Some of these initiatives point to improve digital government, connectivity, and digital economy [15]. Particularly, the government plans to deploy a series of initiatives to foster Chilean digital economy through programs for SMEs facilitating the adoption of e-commerce. For instance, strategies associated with technical support for business process innovation, digital marketing, online sales, and web page design. In addition, the 2020 Digital Agenda includes the development of electronic means of payment to support small businesses and facilitate secure payment [15]. However, the results of this study shows that there are other strategies that should be taken into account in order to promote e-commerce among SMEs. First, our results show that innovation is an important personality trait that may boost e-commerce. Government could include some programs to help determining personality traits of managers/owners of SMEs and reinforce some beliefs about the importance of drivers of e-commerce for less innovative managers.

Second, Chilean government could focus on specific training programs to help in changing beliefs of less innovative managers of SMEs. Kessy and Temu [39] examined the positive impact of training in changing behavior and 
characteristics of business and owners of small companies. On a similar line, Barrera [7] found that very small businesses in Chile that have financed training adopt more internet and e-commerce related activities than their counterparts who have not been subject to training. Lawson et al. [44] indicated that the lack of education and IT specific knowledge is an important barrier to incorporate e-commerce in organizations. Going further, Nasri and Iskandar [61] proposed a competency model in e-commerce training for small businesses. These initiatives could be added to the 2020 Chilean Digital Agenda since the incorporation of e-commerce not only puts into place new technology, it also involves changes in the way business is done.

Third, practitioners should consider e-commerce barriers and develop some actions to overcome them. One of the most significant constraints cited in the literature [22], [63], and also found in this study, is security. The perception that e-commerce is not secure is an important impediment that influences the attitude toward using e-commerce. Therefore, practitioners should focus on, among other measures, choosing a secure e-commerce platform, improving the authentication process, providing policies for strong passwords and login rules, and arranging security training for their employees.

Four, government training programs could also focus on increasing self-efficacy of managers/owners of SMEs. Selfefficacy is defined as a personal judgement of how well one can execute courses of action required to deal with prospective situations [6]. It is known that to be able to innovate, for example to adopt new technology, requires a high degree of self-efficacy [70]. In fact, there is evidence of the importance of creativity self-efficacy judgments in workplace innovation [10]. Mathisen and Bronnick [51] stated that what a person is capable of doing is dictated by the observation he or she does about the behaviors of other people and the appraisal of the consequences of that behaviors. The experience of mastering a task is the most important factor determining a person's self-efficacy. Success raises self-efficacy, while failure lowers it. As an additional strategy, government could put together a database with previous successful experiences of managers/owners of SMEs who have already adopted ecommerce.

From a theoretical standpoint, there are several important implications. First, we found that drivers and obstacles make up the positive or negative attitude toward adopting e-commerce. Previous studies concerning SMEs in developing countries have focused on identifying these drivers and obstacles and determining a factor structure of their underlying components [13], [38]. Further studies based on the TPB have included other antecedents of attitude when explaining the intention to use e-commerce-related technologies. Perceived risk, lifestyle, trusting the buyer and the website, and perceived fit are some of them [35], [71], [96]. Moreover, we remarked that attitude is the strongest predictor of the intention to use e-commerce and even duplicates the significance level of the PBC construct $(0.32$ vs. $0.15, p<0.001$ and $p<0.05$ respectively). Future research could validate these findings and consider drivers and barriers as predictors of attitude toward e-commerce adoption. Second, even though previous research has discarded PBC as a significant factor that influences the intention to use e-commerce [25], [60], in this current study we saw that the inclusion of PBC explains the TPB model better. Further, we noticed a significant impact of this construct when considering managers/owners' innovativeness as a categorical moderator of the relationship. For managers/owners with a low level of innovativeness, PBC is a key predictor of intention. Third, innovativeness emerged as a significant moderator of the TPB model's hypothesized relationships. This is an important addition to the model and validates the findings of Borrero et al. [8] in a different context. Therefore, this study extends our knowledge by adding innovativeness as a relevant moderator to add to those of gender, age, voluntariness and experience, which are usually considered in the UTAUT and UTAUT2 models [91], [92]. Finally, we found that obstacles are more important than drivers $(0.38$ vs $0.25, \quad p<0.001)$ when managers/owners evaluate the possible use of e-commerce. Future research could focus on investigating the reasons for this finding.

\section{Conclusions}

This paper studied the differences in the adoption of e-commerce in SMEs associated with the level of managers/owners' innovativeness. It extended the Theory of Planned Behavior by including drivers and obstacles as antecedents of the attitude to adopt e-commerce. Data was collected from managers/owners of SME in a developing country by means of a questionnaire. A Partial Least Squares multi-group test was employed to validate the hypotheses. It is concluded that this well-known theory certainly explains the adoption of e-commerce among Chilean managers/owners of SMEs; significant relationship exists between attitude, subjective norm, and perceived behavioral control and intention to use e-commerce. Particularly, attitude turned out to be the strongest predictor of the intension to adopt e-commerce. As it was presumed, drivers and obstacles predict the attitude toward using ecommerce; drivers impact positively and obstacles impact negatively the behavior in question. When analyzing these relationships based on the level of managers/owners' innovativeness, we found that drivers are significant predictors of the attitude for more innovative managers/owners while obstacles are significant predictors of the attitude for less innovative managers/owners. We highlight that this research is the first to apply the TPB in a multi-group analysis in Chile which includes innovativeness as an important personality trait to be considered when SMEs think about implementing e-commerce.

These results are similar to previous research based on the TPB model and perceptions of managers/owners of SMEs ([25], [60], [77]). Irrespective of their level of innovativeness, attitude and subjective norm are good predictors of e-commerce adoption. However, perceived behavioral control is significant only for less innovative 
managers/owners. Innovativeness may explain why the TPB's perceived behavioral control construct has shown inconsistent results in the literature. Moreover, innovativeness may be negatively correlated with uncertainty avoidance [31]. As Ramirez-Correa et al. [74] pointed out, having a culture with a high uncertainty avoidance may explain Chilean online consumer behavior. Similarly, the uncertainty avoidance dimension may affect the innovativeness of the decision makers of SMEs. This then may influence their intention to participate in e-commerce. Thus, we provide new insights for both SMEs and researchers. Finally, we highlight that this research is the first to apply the TPB in a multi-group analysis in Chile which includes innovativeness as an important personality trait to be considered when SMEs think about implementing e-commerce.

Important practical and theoretical implications can be derived from this study. In order to encourage managers/owners of SMEs to implement e-commerce and take advantage of its benefits, one should change their attitudes and underline the social referents that influence the adoption decision. Government should promote programs to help determining personality traits of managers/owners of SMEs and reinforce beliefs about the importance of drivers of e-commerce. Training programs and the creation of database with previous experiences about e-commerce adoption could help to increase managers/owners' perceived self-efficacy, which, in turn, would boost innovation. From a theoretical point of view, this study has contributed to generate a more comprehensive research model that includes drivers and obstacles that cause positive or negative attitudes toward adopting ecommerce and that considers innovativeness as an important categorical moderator to better understand the role of the perceived behavioral control construct.

Even though we followed a rigorous research methodology, this research is not without limitations. The number of managers/owners with low and high levels of innovativeness is not balanced. The first group is $75.7 \%$ of the sample while the second is $24.3 \%$. In addition, SMEs may be more or less inclined to adopt e-commerce depending on the stage of the innovation process they are at [81]. SMEs at an early stage may be less disposed to start e-commerce. On the other hand, SMEs at a later point in the innovation curve may be more prepared to implement e-commerce. Yet, we did not collect this information in the survey. Finally, we can mention that even though the sample size of this study is small, it represents almost all of the industry sectors in Chile. Our sample is mostly comprised of SMEs in the commerce $(27.6 \%)$, services $(27.1 \%)$, and manufacturing $(15.2 \%)$ sectors. According to the Longitudinal Survey of Enterprises [56], SMEs in Chile are mainly in the commerce, services, and manufacturing segments.

Future research should focus on validating the role of innovativeness in the assessment of e-commerce adoption by mangers/owners of SMEs in other contexts. Since Chile shares some cultural characteristics with other Latin American countries, it is expected that the results of this study may help other developing countries to determine salient beliefs toward e-commerce adoption. In a similar line of inquire, future studies could focus on knowing managers/owners' characteristics/personality traits and on comparing strategies and good practices between companies that have and have not adopted e-commerce. In addition, future investigation could validate the research model and consider other moderators associated with personality traits, such as the optimism construct proposed in the Technology Readiness Index [68], [69]. Moreover, the proposed research model could be validated using other technologies that may facilitate SMEs in their way of doing businesses. Examples of this are cloud platforms and the Internet of Things which, along with e-commerce, will be the leading digital transformations in Latin America in the years to come [37]. Finally, a longitudinal study may be conducted in order to verify whether SMEs adopted ecommerce.

\section{Acknowledgments}

This work was funded by CONICYT - FONDECYT 11060419.

\section{References}

[1] M.A. Abou-Shouk, W.M. Lim, and P. Megicks, Using competing models to evaluate the role of environmental pressures in ecommerce adoption by small and medium sized travel agents in a developing country, Tourism Management, vol. 52, pp. 327-339, 2016.

[2] R. Agarwal and J. Prasad, A conceptual and operational definition of personal innovativeness in the domain of information technology, Information Systems Research, vol. 9, no. 2, pp. 204-215, 1998.

[3] A. Ajzen, The theory of planned behavior, Organizational Behavior and Human Decision Processes, vol 50, no. 2, pp. 179-211, 1991.

[4] N. C. Astuti and R.A. Nasution, Technology readiness and e-commerce adoption among entrepreneurs of SMEs in Bandung city, Indonesia, Gadjah Mada International Journal of Business, vol. 16, no. 1, pp. 69-88, 2014.

[5] ATKearney. (2015) Global retail e-commerce keeps on clicking. ATKearney. [Online]. Available: http://www.atkearney.com

[6] A. Bandura, Self-efficacy mechanism in human agency, American Psychologist, vol. 37, no 2, pp. 122-147, 1982.

[7] G. Barrera, Relación de capacitación con adopción de internet y e-commerce: Diferencias entre microemprendedores de Chile, Información Tecnológica, vol. 28, no. 6, pp. 61-70, 2017. 
[8] J.D. Borrero, S. Y. Yousafzai, U. Javed, and K.L. Page expressive participation in Internet social movements: Testing the moderating effect of technology readiness and sex on student SNS use, Computers in Human Behavior, vol. 30, pp. 39-49, 2014

[9] D. J. Brein, T. J.Fleenor, S. W. Kim, and E. Krupat, Using the theory of planned behavior to identify predictors of oral hygiene: A collection of unique behaviors, Journal of Periodontology, vol.87, no. 3, pp. 312-319, 2016.

[10] A. Carmeli and J. Schaubroeck, The influence of leaders' and other referents' normative expectations on individual involvement in creative work, The Leadership Quarterly, vol. 18, pp. 35-48, 2007.

[11] M. K. Chang, - Predicting unethical behavior: A comparison of the theory of reasoned action and the theory of planned behavior, Journal of Business Ethics, vol. 17, no. 16, pp. 1825-1834, 1998

[12] F. D. Davis, Perceived usefulness, perceived ease of use, and user acceptance of information technology, Mis Quarterly, vol. 13, no. 3, pp. 319-340, 1989.

[13] A. O. Daviy and V. Rebiazina, Investigating barriers and drivers of the e-commerce market in Russia, Higher School of Economics Research, Russia, Working Paper No. WP BRP 40/Man, 2015.

[14] P. Devolder, B. Pynoo, B. Sijnave, T. Voet, and P. Duyck, Framework for user acceptance: Clustering for finegrained results, Information \& Management, vol. 49, no. 5, pp. 233-239, 2012.

[15] Digital Agenda. (2015) Seguimiento de la Agenda 2020. Agenda Digital 2020. [Online]. Available: http://www.agendadigital.gob.cl/\#/

[16] A. I. Elbeltagi, Y. Al Sharji, G. Hardaker, and A. Elsetouhi, The role of the owner-manager in SMEs' adoption of information and communication technology in the United Arab Emirates, Journal of Global Information Management, vol. 21, no. 2, pp. 23-50, 2013.

[17] eMarketer. (2019) Worldwide retail ecommerce sales: eMarketer's updated estimates and forecast through 2019. eMarketer. [Online]. Available: http://www.emarketer.com

[18] N. Erdoğmuş and M. Esen, An investigation of the effects of technology readiness on technology acceptance in e-HRM, Procedia-Social and Behavioral Sciences, vol. 24, pp. 487-495, 2011.

[19] M. Ghobakhloo, M. S. Sabouri, T. S. Hong, and N. Zulkifli, Information technology adoption in small and medium-sized enterprises; an appraisal of two decades literature, Interdisciplinary Journal of Research in Business, vol. 1, no. 7, pp. 53-80, 2011.

[20] R. E. Goldsmith and G. R. Foxall, The measurement of innovativeness, in International Handbook on Innovation (L. V. Shavinina, Ed.), Oxford, UK: Elsevier Science, 2003, pp. 321-328.

[21] S. Godoy and E. Helsper, La alargada sombra de la exclusión digital: Una comparación entre Reino Unido y Chile, in Un Mundo Conectado: Las TIC Transforman Sociedades, Culturas y Economías (B. van Bark, Ed.). Madrid, Barcelona: Ariel / Fundación Telefónica, 2011, pp. 135-160.

[22] S. Godoy, C. Labarca, N. Somma, M. Gálvez, and M. Sepúlveda, Circumventing communication blindspots and trust gaps in technologically-mediated corporate relationships: The case of Chilean business-to-consumer ecommerce, Journal of Theoretical and Applied Electronic Commerce Research, vol. 10, no. 2, pp. 19-32, 2015.

[23] E. E. Grandón and N. Duran, Use of electronic commerce for the potentiation of Latin American SMEs: Exploratory study of barriers and drivers, in Proceedings of the XLIII Asamblea Anual del Consejo Latinoamericano de Escuelas de Administración CLADEA, Puebla, México, 2008.

[24] E. E. Grandón and P. P. Mykytyn, Theory-based instrumentation to measure the intention to use electronic commerce in small and medium sized businesses, Journal of Computer Information Systems, vol. 44, no. 3, pp. 44-57, 2004.

[25] E. E. Grandón, S. A. Nasco and P. P. Mykytyn, Comparing theories to explain e-commerce adoption, Journal of Business Research, vol. 64, no. 3, pp. 292-298, 2011.

[26] E. E. Grandón and J. M. Pearson, Electronic commerce adoption: an empirical study of small and medium US businesses, Information \& Management, vol. 42, no. 1, pp. 197-216, 2004.

[27] J. F. Hair, G. T. Hult, C. M. Ringle, and M. Sarstedt, A Primer on Partial Least Squares Structural Equation Modeling (PLS-SEM) (2nd ed.). Thousand Oaks: Sage. 2014.

[28] L. M. Hassan, E. Shiu and S. Parry, Addressing the cross-country applicability of the theory of planned behaviour (TPB): A structured review of multi-country TPB studies, Journal of Consumer Behaviour, vol. 15, no. 1, pp. 72-86, 2016.

[29] J. Henseler, G. Hubona and P. A. Ray, Using PLS path modeling in new technology research: Updated guidelines, Industrial Management \& Data Systems, vol. 116, no. 1, pp. 2-20, 2016.

[30] S. Herrera, G. Lever, A. Myrick, and M. Sepúlveda, La empresa chilena en la economía de la información. Principales resultados de la segunda encuesta BIT-Chile 2007, Cámara de Comercio de Santiago, Facultad de Comunicaciones UC, Santiago, Technical Report 1050769, 2008.

[31] G. H. Hofstede, Culture's consequences: Comparing values, behaviors, institutions and organizations across nations. Thousand Oaks, CA: Sage, 2001

[32] W. T. Hsu, H. L. Chen and C. Y. Cheng, Internationalization and firm performance of SMEs: The moderating effects of CEO attributes, Journal of World Business, vol. 48, no. 1, pp. 1-12, 2013.

[33] L. Hu, and P. M. Bentler, Fit indices in covariance structure modeling: sensitivity to underparameterized model misspecification, Psychological Methods, vol. 3, no. 4, pp. 424-453, 1998.

[34] G. T. M. Hult, R. F. Hurley and G. A. Knight, Innovativeness: Its antecedents and impact on business performance, Industrial Marketing Management, vol. 33, no. 5, pp. 429-438, 2004.

[35] S. Y. Hung, K. Z. Tang, C. M. Chang, and C. D. Ke, User acceptance of intergovernmental services: An example of electronic document management system, Government Information Quarterly, vol. 26 no. 2, pp. 387-397, 2009. 
[36] J. Hwang, H. Lee, K. Kim, H. Zo, and A. P. Ciganek, Cyber neutralisation and flaming, Behaviour Information Technology, vol. 35, no. 3, pp. 210-224, 2016.

[37] IDC. IDC FutureScape: Latin America IT Industry 2016 predictions-leading digital transformation to scale, 2015

[38] M. Kartiwi and R. C. MacGregor, Electronic commerce adoption barriers in small to medium-sized enterprises (SMEs) in developed and developing countries: A cross-country comparison, Journal of Electronic Commerce in Organizations (JECO), vol. 5, no. 3, pp. 35-51, 2007.

[39] S. Kessy and S.S. Temu, The impact of training on performance of micro and small enterprises served by microfinance institutions in Tanzania, Research Journal of Business Management, vol. 4, no 2, pp. 103-111, 2010.

[40] J. Koenigstorfer and A. Groeppel-Klein, Consumer acceptance of the mobile internet, Marketing Letters, vol. 23 , no. 4, pp. 917-928, 2012

[41] P. Kristensson, A. Gustafsson and T. Archer, Harnessing the creative potential among users, Journal of Product Innovation Management, vol. 21, no. 1, pp. 4-14, 2004.

[42] S. Kumia, J. Choudrie, R. M. Mahbubur, and B. Alzougool, E-commerce technology adoption: A Malaysian grocery SME retail sector study, Journal of Business Research, vol. 68, no. 9, pp. 1906-1918, 2015.

[43] S. Y. Lam, J. Chiang and A. Parasuraman, The effects of the dimensions of technology readiness on technology acceptance: An empirical analysis, Journal of Interactive Marketing, vol. 22, no. 4, pp. 19-39, 2008.

[44] R. Lawson, C. Alcock, J. Cooper, and L. Burgess, Factors affecting adoption of electronic commerce technologies by SMEs: An Australian study, Journal of Small Business and Enterprise Ddevelopment, vol. 10, no 3, pp. 265-276, 2003

[45] H. S. Lee, Examining neighborhood influences on leisure-time walking in older Korean adults using an extended theory of planned behavior, Landscape and Urban Planning, vol. 148, pp. 51-60, 2016.

[46] C. H. Lin, H. Y. Shih and P. J. Sher, Integrating technology readiness into technology acceptance: The TRAM model, Psychology \& Marketing, vol. 24, no. 7, pp. 641-657, 2007.

[47] J. S. C. Lin and P. L. Hsieh, Refinement of the technology readiness index scale. A replication and crossvalidation in the self-service technology context, Journal of Service Management, vol. 23, no. 1, pp. 34-53, 2012.

[48] Longitudinal Survey of Companies. (2015) Tercera encuesta longitudinal de empresas (ELE-3), Chilean Ministry of Economy, Promotion and Tourism. [Online]. Available: http://www.economia.gob.cl/estudios-yencuestas/tercera-encuesta-longitudinal-de-empresas

[49] R. C. MacGregor and L. Vrazalic, A basic model of electronic commerce adoption barriers: A study of regional small businesses in Sweden and Australia, Journal of Small Business and Enterprise Development, vol. 12, no. 4, pp. 510-527, 2005.

[50] T. J. Madden, P. S. Ellen and I. Ajzen, A comparison of the theory of planned behavior and the theory of reasoned action, Personality and Social Psychology Bulletin, vol. 18, no. 1, pp. 3-9, 1992.

[51] G. E. Mathisen and K. S. Bronnick, Creative self-efficacy: An intervention study, International Journal of Educational Research, vol. 48, no. 1, pp. 21-29, 2009.

[52] B. McCarthy, The impact of the entrepreneur's personality on the strategy-formation and planning process in SMEs, Irish Journal of Management, vol. 24, no. 1, pp. 154-172, 2003.

[53] R. R. McCrae, P. T. Costa, F. Ostendorf, A. Angleitner, M. Hrebickova, and M. D. Avia, Nature over nurture: Temperament, personality, and life span development, Journal of Personality and Social Psychology, vol. 78, no. 1 , pp. $173-186,2000$

[54] B. Meng and K. Choi, Extending the theory of planned behaviour: testing the effects of authentic perception and environmental concerns on the slow-tourist decision-making process, Current Issues in Tourism, vol. 19, no. 6, pp. 528-544, 2016.

[55] A. I. Miladi, Governance for SMEs: Influence of leader on organizational culture, International Strategic Management Review, vol. 2, no. 1, pp. 21-30, 2014

[56] MINECON, Longitudinal Survey of Enterprises in Chile (ELE). Chile: Chilean Ministry of Economy, 2011

[57] MINECON, Antecedents for the Revision of the Classification Criteria of the SME Statute. Chile: Chilean Ministry of Economy, 2014.

[58] MINECON, Consulting for the Study of Diagnosis of Electronic Commerce in Chile. Chile: Chilean Ministry of Economy, 2016

[59] S. Nadkarni and P. Herrmann, CEO personality, strategic flexibility, and firm performance: The case of the Indian business process outsourcing industry, Academy of Management Journal, vol. 53, no. 5, pp. 1050-1073, 2010.

[60] S. A. Nasco, E. E. Grandón, and P. P. Mykytyn, Predicting electronic commerce adoption in Chilean SMEs, Journal of Business Research, vol. 61, no. 6, pp. 697-705, 2008.

[61] N. Nasri and Y. P. Iskandar, Pedagogy paradigm: Competency in e-commerce training for entrepreneurs, in Proceedings 2015 International Conference on Technology, Informatics, Management, Engineering \& Environment (TIME-E), Samosir, 2015, pp. 82-86.

[62] J. J. Newham, C. Allan, P. Leahy-Warren, D. Carrick-Sen, and F. Alderdice, Intentions toward physical activity and resting behavior in pregnant women: Using the theory of planned behavior framework in a cross-sectional study, Birth-Issues in Perinatal Care, vol. 43, no. 1, pp. 49-57, 2016.

[63] M. Niranjanamurthy and D. Chahar, The study of e-commerce security issues and solutions, International Journal of Advanced Research in Computer and Communication Engineering, vol. 2, no. 7, 2013.

[64] C. Nitzl, The use of partial least squares structural equation modelling (PLS-SEM) in management accounting research: Directions for future theory development, Journal of Accounting Literature, vol. 37, pp. 19-35, 2016. 
[65] OECD, Measuring the Digital Economy - A New Perspective. Paris: OECD Publishing, 2014

[66] OECD, Chile, in Financing SMEs and Entrepreneurs 2016: An OECD Scoreboard. Paris: OECD Publishing, 2016.

[67] OECD. (2018, April) Country statistical profile: Chile. OECD iLibrary. [Online]. Available: https://www.oecdilibrary.org/economics/country-statistical-profile-chile-2018-2 csp-chl-table-2018-2-en

[68] A. Parasuraman, Technology readiness index (TRI) a multiple-item scale to measure readiness to embrace new technologies, Journal of Service Research, vol. 2, no. 4, pp. 307-320, 2000.

[69] A. Parasuraman and C. L. Colby, An updated and streamlined technology readiness index: TRI 2.0., Journal of Service Research, vol. 18, no. 1, pp. 59-74, 2015.

[70] V. Prabhu, C. Sutton and W. Sauser, Creativity and certain personality traits: Understanding the mediating effect of intrinsic motivation, Creativity Research Journal, vol. 20, pp. 53-66. 2008.

[71] F. Quevedo-Silva, O. Freire, D. d. O.Filho, M. M. Brandao, G. Isabella, and L. B. Moreira, Intentions to purchase food through the internet: Developing and testing a model, British Food Journal, vol. 118, no. 3, pp. 572-587, 2016.

[72] R. Rahayu and J. Day, Determinant factors of e-commerce adoption by SMEs in developing country: evidence from Indonesia, Procedia-Social and Behavioral Sciences, vol. 195, pp. 142-150, 2015.

[73] T. Ramayah, N. S. Ling, S. K. Taghizadeh, and S. A. Rahman, Factors influencing SMEs website continuance intention in Malaysia, Telematics and Informatics, vol. 33, no. 1, pp. 150-164, 2016.

[74] P. Ramirez-Correa, F. J. Rondan-Cataluna and J. Arenas-Gaitan, An empirical analysis of mobile Internet acceptance in Chile, Information Research - An International Electronic Journal, vol. 19, no. 3, pp. 113-134, 2014

[75] A. Rauch and M. Frese, Psychological approaches to entrepreneurial success: A general model and an overview of findings, International Review of Industrial and Organizational Psychology, vol. 15, pp. 101-142, 2000.

[76] A. Rauch and M. Frese, Let's put the person back into entrepreneurship research: A meta-analysis on the relationship between business owners' personality traits, business creation, and success, European Journal of Work and Organizational Psychology, vol. 16, no. 4, pp. 353-385, 2007.

[77] K. Riemenschneider, D. A. Harrison and P. P. Mykytyn, Understanding it adoption decisions in small business: Integrating current theories, Information and Management, vol. 40, no. 4, pp. 269-285, 2003.

[78] K. Riemenschneider and V. R. McKinney, Assessing belief differences in small business adopters and nonadopters of web-based e-commerce, Journal of Computer Information Systems, vol. 42, no. 2, pp. 101-107, 2001

[79] M. Ringle, S. Wende and J. M. Becker, Smartpls 3. Hamburg: SmartPLS, 2014.

[80] I. Rodriguez del Bosque and A. Herrero Crespo, How do internet surfers become online buyers? an integrative model of e-commerce acceptance, Behaviour \& Information Technology, vol. 30, no. 2, pp. 161--180, 2011.

[81] M. Rogers, Diffusion of Innovations. New York: Simon and Schuster, 2010.

[82] M. Rogers and F. F. Shoemaker, Communication of Innovations: A Cross-Cultural Approach. New York, USA: Free Press, 1971

[83] S. A. Salim, D. Sedera, S. Sawang, A. H. E. Alarifi, and M. Atapattu, Moving from evaluation to trial: How do SMEs start adopting cloud ERP?, Australasian Journal of Information Systems, vol. 19, pp. 219-245, 2015.

[84] Santiago Chamber of Commerce. (2016) La economía digital en Chile 2016. Cámara de Comercio de Santiago. [Online]. Available: http://www.ccs.cl/html/economia digital/comite comercio electronico.html

[85] Y. Y. Shih and K. T. Fang, The use of a decomposed theory of planned behavior to study internet banking in Taiwan, Internet Research-Electronic Networking Applications and Policy, vol. 4, no. 3, pp. 213-223, 2004.

[86] S. Shin and W. J. Lee, The effects of technology readiness and technology acceptance on NFC mobile payment services in Korea, Journal of Applied Business Research, vol. 30, no. 6, pp. 1615-1626, 2014

[87] R. Thakur and M. Srivastava, Adoption readiness, personal innovativeness, perceived risk and usage intention across customer groups for mobile payment services in India, Internet Research, vol. 24, no. 3, pp. 369-392, 2014.

[88] A. H. Turan, Internet shopping behavior on Turkish customers: comparison of two competing models, Journal of Theoretical and Applied Electronic Commerce Research, vol 7, no. 1, pp. 77-93, 2012.

[89] UNCTAD. (2015) Information economy report 2015 - unlocking the potential of e-commerce for developing countries. United Nations. [Online]. Available: http://unctad.org/en/PublicationsLibrary/ier2015 en.pdf

[90] E. M. Van Raaij and J. J. Schepers, The acceptance and use of a virtual learning environment in China, Computers \& Education, vol. 50, no. 3, pp. 838-852, 2008.

[91] V. Venkatesh, M. G. Morris, G. B. Davis, and F. D. Davis, User acceptance of information technology: Toward a unified view, Mis Quarterly, vol. 27, no. 3, pp. 425-478, 2003.

[92] V. Venkatesh, J. Y. L. Thong and X. Xu, Consumer acceptance and use of information technology: Extending the unified theory of acceptance and use of technology, Mis Quarterly, vol. 36, no. 1, pp. 157-178, 2012.

[93] R. Walczuch, J. Lemmink and S. Streukens, The effect of service employees' technology readiness on technology acceptance, Information \& Management, vol. 44, no. 2, pp. 206-215, 2007.

[94] S. Walczak and G. L. Borkan, Personality type effects on perceptions of online credit, Journal of Theoretical and Applied Electronic Commerce Research, vol. 11, no. 1, pp. 67-83, 2016.

[95] J. Wincent and M. Westerberg, Personal traits of CEOs, inter-firm networking and entrepreneurship in their firms: Investigating strategic SME network participants, Journal of Developmental Entrepreneurship, vol. 10, no. 3, pp. 271-284, 2005. 
[96] C. Yen and C. M. Chang, Unity is strength: understanding users'group buying behavior in Taiwan from a collectivism perspective, Journal of ElectronicCommerce Research, vol. 16, no.2, pp. 109-122, 2015.

[97] S. Yousafzai and M. Yani-de-Soriano, Understanding customer-specific factors underpinning internet banking adoption, International Journal of Bank Marketing, vol. 30, no. 1, pp. 60-81, 2012.

[98] S. Zhu and J. Chen, E-commerce use in urbanising China: The role of normative social influence, Behaviour \& Information Technology, vol. 35, no. 5, pp. 357-367, 2016. 